\title{
Pertencimento étnico e compromissos morais: curdos em diáspora na Dinamarca e os direitos humanos no Curdistão
}

\author{
Ethnic belonging and moral commitments: diaspora Kurds \\ in Denmark and human rights in Kurdistan
}

\section{Tiago Duarte Dias}

Brasil. Universidade Federal Fluminense. Graduado em Relações Internacionais pela Universidade Federal Fluminense. Mestre em Antropologia pela UFF. Doutorando em Antropologia pela UFF. ID ORCID: http://orcid.org/0000-0002-1413-7310.E-mail: tiago_ddias@hotmail.com

\section{Resumo}

O conceito de alteridade significa a capacidade de se reconhecer no outro e de se colocar em seu lugar. A população curda em diáspora e a população curda no território curdo - por se considerarem mutuamente como pertencentes ao mesmo povo - mantêm fortes laços sociais, políticos e culturais entre si. Dentre as populações em diáspora ao redor do mundo é extremamente comum que grupos curdos se organizem, tanto como forma de criar laços de solidariedade em relação a questões políticas envolvendo o Curdistão quanto como forma de agir em prol dos curdos sofrendo no Curdistão. Este artigo busca analisar como tal movimento ocorreu com grupos na capital dinamarquesa durante a ofensiva do grupo terrorista Isis (Islamic State in Iraq and Syria) nas montanhas de Sinjar, no Curdistão iraquiano. A utilização do conceito de direitos humanos pelos grupos curdos em Copenhague faria parte de uma estratégia que mobilizaria atores políticos dinamarqueses em intervir em prol de uma minoria étnica e religiosa que estaria sofrendo uma tentativa de genocídio, ao mesmo tempo em que as disputas políticas da população curdo-dinamarquesa serviriam como pano de fundo. Logo, serão discutidas as formas pelas quais os direitos humanos e as moralidades advindas desse conceito são articuladas pelos indivíduos. 
Invocando a história curda - na qual, historicamente, os direitos humanos têm sido sistematicamente negados - e o papel histórico da Dinamarca como defensora dos mesmos direitos, tais atores buscam articular tanto o pertencimento étnico curdo como a identidade dinamarquesa.

Palavras-chave: Direitos Humanos, Curdistão, Dinamarca, Diáspora.

\section{Abstract}

The concept of otherness means the ability of recognizing oneself in the other and placing oneself in their place. Considering themselves to be a part of the same people, the Kurdish population in diaspora and the Kurdish population in Kurdish territory maintain social, political and cultural ties. Among Kurdish populations in diaspora all over the world, it is very common that groups organize themselves both to create solidarity over political matters involving Kurdistan and to act in favour of Kurds suffering in Kurdistan. This article analyzes how such movements occurred in the Danish capital during the ISIS offensive in Mount Sinjar, located in the Iraqi Kurdistan. It suggests that the usage of the concept of human rights by Kurdish groups in Copenhagen is part of a strategy that mobilizes Danish political actors to intervene in favour of an ethnic minority suffering from an attempt of genocide, whereas Kurdish-Danish political disputes serve as a background. Thus, this article will discuss the ways in which the individuals articulate Human Rights, and the morality that comes from this concept. By invoking Kurdish history-who were historically denied of their human rights-and the historical role that Denmark has of defending such rights, these actors aim to articulate both Kurdish ethnic belonging and Danish identity.

Keywords: Human Rights, Kurdistan, Denmark, Diaspora.

\section{INTRODUÇÃO}

Os curdos são uma etnia com entre 36,4 milhões e 45,6 milhões de habitantes (THE KURDISH..., 2017), de acordo com o Instituto Curdo de Paris, e seu território de origem se encontra numa região dividida entre quatro estados: Turquia, Irã, Iraque e Síria. Fora de tal território, que doravante será 
chamado de Curdistão, há uma população em diáspora bastante significativa em países da União Europeia, como Alemanha, Suécia, França, Reino Unido e Dinamarca, além de América do Norte, Israel e países da antiga Cortina de Ferro, como o Cazaquistão e a Armênia.

Na diáspora dinamarquesa, segundo estimativas, a população curda varia entre 25 mil e 30 mil indivíduos (DIASPORA..., 2016). Fora a presença esporádica de poucas pessoas, o início da presença curda na Dinamarca tem início com a vinda dos trabalhadores convidados nos anos 1950, como mão de obra, vindos da Turquia. Entre muitos desses trabalhadores de nacionalidade turca chamados para trabalhar, especialmente na indústria dinamarquesa, alguns eram de etnia curda (JØRGENSEN, 2010). As décadas seguintes trariam muitos familiares desses mesmos trabalhadores, em um primeiro instante de maneira mais fácil, até que o governo dinamarquês passa a coibir e dificultar a imigração para o país, além, é claro dos descendentes desses trabalhadores, que já estariam estabelecidos no território dinamarquês. Para além disso, houve também um fluxo de refugiados dos diversos conflitos presentes nos países com população curda. Da própria Turquia viriam refugiados do conflito civil entre o governo turco e o Partido dos Trabalhadores do Curdistão (PKK); do Irã e Iraque viriam refugiados do conflito entre ambos os países nos anos 1980; e, posteriormente, refugiados iranianos e iraquianos perseguidos por motivos étnicos, religiosos ou políticos; no caso dos iraquianos, também viriam indivíduos afetados pela invasão norte-americana ocorrida em 2003. E, por último, a Guerra Civil na Síria iniciada em 2014 traria também a última leva de refugiados de guerra, mesmo a Dinamarca não sendo um destino prioritário, como foram a Alemanha e a Suécia.

Assim, o fluxo de indivíduos de etnia curda, junto com a presença de curdos de segunda, terceira ou até quarta gerações, levaria a uma população cujos números variariam entre 25 mil e 30 mil indivíduos ${ }^{1}$. A presença curda em território dinamarquêsé, portanto, uma presença com algumas décadas de história e que

\footnotetext{
Apesar do governo dinamarquês ter estatísticas extremamente precisas sobre o número de indivíduos das mais diversas nacionalidades presentes em seu território, é difícil obter estatísticas precisas sobre os números de curdos, pelos motivos políticos citados (a divisão em quatro Estados).
} 
levaria, inclusive, ao surgimento de figuras políticas relevantes dentro da vida social dinamarquesa, incluindo membros do Parlamento Dinamarquês de ascendência curda, além de escritores, artistas, jornalistas e pesquisadores curdo-dinamarqueses. Acontecimentos relacionados à causa curda também têm destaque na imprensa nacional, como os eventos que serão narrados neste artigo.

No verão de 2015, o grupo terrorista Isis (Islamic State in Iraq and Syria) realizaria ofensivas no território iraquiano em uma região de maioria yazidi. Os yazidis são um grupo religioso de origem étnica curda, cuja origem é anterior ao surgimento do islã e com elementos de religiões da Mesopotâmia Antiga e que traçam sua origem religiosa desde antes do surgimento das principais religiões monoteístas do Oriente Médio, fazendo parte de uma narrativa étnica curda que se estende há mais de quatro milênios. O grupo fundamentalista e terrorista Isis os via como um grupo herético e, assim, passaram a persegui-los. Milhares de pessoas seriam obrigadas a fugir de seus lares, levadas como prisioneiros de guerra, escravizadas e vendidas como escravas sexuais ou assassinadas pelo Isis nessa ofensiva. Durante a ofensiva, um grupo de yazidis se refugiaria nas montanhas de Sinjar (Shingâl, em curdo). O grupo teria fugido do Isis sem levar mantimentos ou água, portanto sua segurança era um fator extremamente frágil. Diante de tal situação, grupos políticos curdo-dinamarqueses organizariam demonstrações em frente ao Parlamento Dinamarquês para exigir que o governo local agisse de forma a prestar apoio militar e humanitário aos yazidis. E é com base nessa manifestação - além de uma subsequente com o mesmo objetivo e, também, da experiência etnográfica de quatro meses do autor em companhia de curdos na Dinamarca de maneira geral - que o artigo se desenvolverá.

\section{IDENTIDADE CURDA E A CAUSA CURDA: ARTICULAÇÕES ENTRE PERSEGUIÇÃO E POLÍTICA NA DIÁSPORA CURDO-DINAMARQUESA}

Conforme citado anteriormente, os curdos se originaram em um território ocupado por quatro estados distintos, sendo, portanto, um etnia sem um 
Estado-nação, ao mesmo tempo em que são minoria étnica relevante nesses quatro Estados. Ao longo de sua história nesses quatro Estados, os curdos sofreriam diversos tipos de perseguição em relação a seus direitos humanos. A Declaração Universal dos Direitos Humanos - o documento mais famoso relacionado ao tópico e promulgado em 1948 - prevê, entre outras coisas, que o indivíduo tem direito às liberdade constitucionais (destacadas nos artigos 18 a 21) como à liberdade de opinião, consciência, pensamento, associação pacífica e de promover ou acessar qualquer tipo de informação por meio de qualquer tipo de mídia. Considerando esses artigos (mas não só esses), diversas vezes vemos os direitos humanos da população curda sendo desrespeitados em seus países de origem.

Na Turquia, após o fim do Império Otomano e com o processo de modernização e ocidentalização iniciado por Mustafa Kemal Atatürk, os curdos passaram a ser vistos não como grupo étnico distinto dos turcos que compõem a maioria da população local, mas como "turcos da montanha" (EDMONDS, 1971). Nesse contexto, o uso e o ensino de idiomas curdos e de expressões culturais relacionadas à etnicidade curda seriam combatidos pelo Estado, e grupos com pretensões irredentistas seriam fortemente reprimidos. $\mathrm{O}$ conflito se acentuaria com o surgimento do PKK, um grupo guerrilheiro de inspiração marxista que até os dias de hoje entra em confronto com o exército turco. No Irã, manifestações de nacionalismo curdo seriam combatidas pelo governo pós-Revolução Islâmica, tanto por desafiar uma base do Estado persa como por motivos étnicos, posto que a maioria dos curdos são sunitas e o Irã é um estado de maioria xiita. Assim como na Turquia, a proibição do uso de idiomas e símbolos curdos ocorre no Irã, com ambos os Estados, por exemplo, contando com um histórico de proibição da impressão de livros em idiomas curdos (HASSANPOUR, 1996). Já no Iraque do Partido Baath, do falecido ditador Saddam Hussein, nos anos 1980, na guerra entre Irã e Iraque se cometeria um genocídio ao utilizarem armas químicas na cidade de Halabja, de maioria curda. Já a Síria contaria com um processo de "arabização" do Norte do país, território historicamente de maioria curda e que seria colonizado por uma população de origem árabe, com lugares com nomenclatura histórica curda 
sendo renomeados em árabe, além da perda da nacionalidade síria de milhares de curdos sob o pretexto de que seriam, na verdade, cidadãos turcos (EDMONDS, 1971).

Tais exemplos demonstram, portanto, o sistemático desrespeito a direitos humanos fundamentais por parte de minorias curdas nos quatro países nos quais o território do Curdistão está localizado. E é nesse contexto, de violação constante de direitos humanos, que uma narrativa sobre estar em refúgio e em diáspora enquanto curdos surge como mais um elemento de coesão (para além do pertencimento étnico) entre diferentes grupos e pessoas que formam a população curda em diáspora (VAN BRUINESSEN, 2000). Isso não significa dizer que todos os curdo-dinamarqueses, ou que todos os curdos na Dinamarca, têm experiências pessoais em relação a sofrerem abusos de direitos humanos por serem curdos, mas, sim, que os abusos sofridos pelos curdos, e a narrativa de que os curdos seriam privados de diversos direitos, é um forte elemento de identificação étnica entre os indivíduos curdos na Dinamarca. Isso tudo conforme me fora relatado por uma jovem curda universitária em uma entrevista em um café em Copenhague e por um jovem curdo em uma outra entrevista, ambas ocorridas no verão de 2014:

Eu vim para a Dinamarca muito cedo com meus pais. Ambos vieram porque a situação política em Diyarbakir, que é basicamente a capital do Curdistão do Norte, no final dos anos 1980 e início dos anos 1990 era extremamente complicada para a gente. Meu pai tinha um tio que morava na Dinamarca, então ele conseguiu que a gente viesse para cá. Meu pai foi a algumas reuniões políticas e chegou a ser interrogado, além de ter tido amigos que foram presos, torturados e outros que lutaram na guerrilha pelo PKK. Como ele já era casado e com uma filha, achou melhor vir para cá.

Nós viemos para a Dinamarca após o genocídio de Halabja. A guerra entre Irã e Iraque foi bastante cruel para os curdos, de ambos os lados. Meu pai era um engenheiro em Kirkuk, maior cidade de maioria curda no Iraque, e resolveu fugir com a minha mãe. Eu nasci já aqui, na Dinamarca. O governo iraquiano de Saddam Hussein foi terrível, e eu fico feliz por ele ter sido morto e, além do mais, com o fim do governo, a situação política dos curdos melhorou. 
Assim, ambos os relatos tratam de situações de perseguição étnica e política em contexto familiar, mesmo que não tenham sido meus interlocutores que sofreram tal perseguição. Histórias de interlocutores, cujos pais ou avós vieram para a Dinamarca como trabalhadores convidados nos anos 1950/1960, não somente vistas como forma de busca de perspectivas financeiras melhores, mas também como saída para a opressão estrutural sofrida por sua identidade étnica. Os trabalhadores curdos convidados que viriam da Turquia para a Dinamarca teriam sua narrativa muitas vezes ressignificada por meio de uma história na qual a ida para a Dinamarca seria uma possibilidade de prosperidade econômica que seria impossível para eles, enquanto curdos, na sociedade turca; além da possibilidade de tais sujeitos se expressarem política, étnica e socialmente enquanto curdos, algo que lhes era negado dentro da Turquia, em um território que os curdos veriam como devendo ser parte do Curdistão. Alguns interlocutores, especialmente os mais velhos, narram certa dicotomia a ser descrita entre motivos políticos e econômicos relacionados à vinda para a Europa. Eles (ou seus pais) teriam vindo para a Dinamarca em busca de oportunidades econômicas e liberdade política.

Se tais indivíduos vieram para a Dinamarca ou se dirigiram para outros países europeus com o objetivo claro de ter liberdade de expressão, ou, ainda, para que pudessem ser curdos sem sofrer perseguição do Estado, ou apenas vieram devido às oportunidades econômicas apresentadas é uma discussão que ainda ocorre dentro da população curda. Alguns informantes me contavam narrativas que seguiam essa linha, enquanto outros afirmavam que vieram para a Dinamarca meramente por uma vida melhor; outros apresentavam narrativas contraditórias, afirmando que seus pais vieram para a Dinamarca por sofrer enquanto curdos, ao mesmo tempo em que eles mesmos construiriam (muitos diriam que "a descobririam") sua identidade enquanto curdos durante sua adolescência e início da vida adulta. De qualquer maneira, a consequência de estar na Dinamarca foi uma possibilidade de articulação política e social à qual eles não teriam acesso no Curdistão. Tal articulação levaria ao surgimento de diversas associações políticas e culturais curdas, ao surgimento de uma 
mídia especializada para a população curda (tanto em curmânji ${ }^{2}$ quanto em dinamarquês), além do engajamento político entre grupos ligados à identidade curda e à política local dinamarquesa.

Conforme fora-me narrado em uma entrevista por um político curdo-dinamarquês do Partido Socialista do Povo (partido de esquerda local), atualmente membro do Parlamento Dinamarquês:

A Dinamarca tem um modelo de bem-estar social bastante efetivo. Dá para viver bem, com todas as condições básicas para uma vida tranquila. A Dinamarca é um país pacífico e com alta qualidade de vida. É claro que nós temos que lutar para que continue sendo assim e para que a gente não perca isso. Ao mesmo tempo, temos que olhar para fora. Os valores dinamarqueses de igualdade deveriam funcionar como um exemplo para o mundo. Eu acredito que nós, curdos, um dia poderemos viver dessa maneira. Com ou sem um estado próprio, eu sonho que possamos viver e nos expressarmos enquanto curdos, dentro do Curdistão.

Fica bastante claro na fala do meu interlocutor um desejo de reproduzir estruturas sociais e políticas que ele encontra na Dinamarca, estruturas que ele, inclusive, almeja ajudar a construir enquanto figura política para a população do Curdistão. Um dos fatores que ele cita é a ideia de igualdade. Em termos políticos e econômicos, a sociedade dinamarquesa é uma das menos desiguais do mundo. A liberdade política desfrutada pela sociedade dinamarquesa e o respeito às liberdades de culto, de organização e de imprensa são elementos nos quais meus interlocutores curdo-dinamarqueses se inspiram como forma de criar um engajamento moral, tanto para outros interlocutores curdo-dinamarqueses como para a população dinamarquesa de maneira geral. O mesmo político citado me afirmaria que sua luta era para que a sociedade dinamarquesa continuasse a ser justa para todos os que nela viviam, ao mesmo tempo que buscava também ser uma liderança dentro da população

\footnotetext{
2 O curmânji é um dos diversos idiomas curdos, sendo o que encontra maior número de falantes e com presença entre todos os territórios curdos. Outros idiomas reconhecidos como parte da identidade étnica curda são o sorâni, o gorani e o zaza.
} 
curdo-dinamarquesa (uma de suas bases eleitorais) e, portanto, defendia que a Dinamarca também deveria ter papel ativo em relação aos direitos humanos voltados ao Curdistão.

Para além desse político curdo, havia uma forte articulação entre o Enhedslisten (Partido Aliança Vermelha e Verde) de extrema-esquerda e diversos grupos curdos da sociedade civil. Havia também a presença de seus membros em manifestações políticas locais. Durante o período de campo do etnógrafo3 vários interlocutores apontaram a presença de políticos do Enhedslisten em eleições na Turquia, agindo como observadores internacionais, além de um forte intercâmbio com o partido turco HDP (Partido Democrático dos Povos), de esquerda e que reúne diversas minorias existentes na Turquia e com forte presença curda. Esse fluxo de informações significa que causas relacionadas à causa curda e aos direitos humanos de populações curdas eram sempre tratados politicamente por figuras políticas de tal partido em discursos no Parlamento Dinamarquês, além de ecoarem por meio das redes sociais dos políticos e do próprio partido. Outros partidos e líderes políticos também buscavam se posicionar diante de eventos relacionados ao Curdistão. Membros de partidos de centro e conservadores, por exemplo, também tiveram espaço nas manifestações nas quais este artigo se baseia.

Logo, a situação política no Curdistão se torna um fato político relevante na política dinamarquesa, conforme será descrito a seguir em relação aos acontecimentos da ofensiva do Estado Islâmico em Sinjar. Há, assim, uma articulação entre membros da população curdo-dinamarquesa e a população dinamarquesa, especialmente em tópicos relacionados a direitos humanos. O discurso relacionado à proteção dos direitos humanos de minorias em situações de opressão apresenta uma série de moralidades que são articuladas vis-à-vis ao capital político em ambos os casos. Também há uma identificação por políticos dinamarqueses de que não somente a população curdo-dinamarquesa teria interesse em relação aos direitos humanos no Curdistão, mas que

3 O antropólogo esteve presente na Dinamarca por aproximadamente quatro meses, três meses durante o verão de 2014 e um pouco mais de mês durante o inverno. Nesse período foram conduzidas entrevistas em inglês e com o uso de dinamarquês em diversas ocasiões. Tanto personalidades locais dentro da política curda quanto indivíduos não engajados no momento ou, ainda, que jamais foram engajados, foram entrevistados. 
o tópico seria de interesse amplo e que a política externa nacional deveria se debruçar sobre tal assunto. De maneira concomitante há, dentro da população curdo-dinamarquesa, uma série de indivíduos que agem de maneiras distintas (tanto de maneira concertada como contrária) no que diz respeito aos direitos humanos no Curdistão, e cujo capital cultural é influenciado pela capacidade de articulação que as organizações e os indivíduos teriam em relação à causa curda de maneira geral.

\section{DIREITOS HUMANOS, A CAUSA CURDA, E O PAPEL DINAMARQUÊS}

Os discursos de defesa dos direitos humanos no Curdistão dentre a população curdo-dinamarquesa se inserem numa rede transnacional em diáspora de articulação política em prol do que pode se chamar de causa curda. Tal articulação surge de um contexto de prosseguimento de disputas de poder dentro da população curda em diáspora. Isso se dá, por exemplo, nos conflitos observados por Bahar Baser (2013) na Alemanha entre partidários do PKKe do Komkar (Komala Kargeren, Associação de Trabalhadores), dois grupos políticos curdos rivais com base no Curdistão turco, o que representaria uma transnacionalização de uma disputa inserida dentro de uma população transnacional. $\mathrm{Ou}$, ainda, na Suécia, especialmente devido a uma política local de incentivo à produção literária das diversas populações que passariam a fazer parte do tecido social sueco, há um número elevado de publicações em idiomas curdos, passando a população curda em diáspora na Suécia a cumprir um papel de difusora desse conhecimento por meio de uma rede transnacional (KHAYATI; DALHSTEDT, 2014). Para além desses exemplos, organizações e manifestações em prol da causa curda podem ser encontradas em diversos países que contam com uma população curda em diáspora.

No caso da Dinamarca, em primeiro lugar, há a adaptação de uma prática dinamarquesa de formar grupos com interesse comum (JØRGENSEN, 2008) para reuniões de cunho social em que as disputas de poder internas a tais 
grupos frequentemente desembocariam na criação de novos grupos compostos pelos indivíduos não satisfeitos com o status quo, em vez de uma disputa pelo seu controle. Essa prática leva, deste modo, ao surgimento de diversos grupos menores relacionados à identidade curda (ao invés de poucos grupos maiores) e que vão se estabelecendo desde a chegada dos primeiros operários convidados (mas, a priori, como grupos também ligados à identidade turca) nos anos 1950/1960 (JØRGENSEN, 2008, 2011). Assim, durante seu trabalho de campo, o autor pôde identificar diversos grupos políticos e sociais relacionados à causa curda com papel relevante, além de diversos indivíduos que circulavam entre eles mantendo, simultaneamente, laços de graus variáveis com mais de um grupo. Tais movimentações e o capital cultural que esses grupos passariam a centralizar são essenciais para a compreensão da dinâmica de articulações relacionadas à causa curda dentro da Dinamarca, especificamente na cidade de Copenhague ${ }^{4}$. Ou seja, há diversos grupos e indivíduos transitando entre eles, buscando tanto articular a população curdo-dinamarquesa e a dinamarquesa em prol da defesa dos direitos humanos de grupos curdos em perigo e, no caso descrito, os yazidis, no Norte do Iraque. Ademais, existe uma disputa entre os grupos curdos e sobre sua relevância para a população curdo-dinamarquesa, além de ser uma disputa dentre os indivíduos que circulam entre diversos grupos e os que se dedicam a somente um deles. Essa disputa se dá tanto no campo ideológico - ou seja, alguns grupos e indivíduos veem que algumas maneiras de articular a defesa dos direitos humanos da população curda seriam mais corretas que outras e que, portanto, deveriam ter sua opinião e seu modus operandi como o ideal por motivos morais - quanto em termos de poder, em que grupos e indivíduos se identificariam como mais eficientes e, consequentemente, deveriam ter mais acesso ao poder de ação e de alocação de recursos.

\footnotetext{
Sobre outras cidades, nada posso afirmar de concreto, exceto comentários feitos por interlocutores baseados em Copenhague. Uma das minhas principais interlocutoras me narraria que, em sua infância, grupos baseados em Aalborg, no Norte do país, distantes aproximadamente cinco horas de Copenhague, organizariam excursões com alguns ônibus para eventos importantes na capital do país. Durante os acontecimentos narrados em no artigo, diversas fotos de manifestações em outras cidades do país, desde Aarhus, a segunda maior, até cidades pequenas e próximas de Copenhague, eram compartilhadas nas redes sociais.
} 
Em segundo lugar, há também na Dinamarca uma possibilidade de articular o tema dos direitos humanos com questões políticas relevantes para o Parlamento Dinamarquês. A Dinamarca, por exemplo, participou das duas últimas invasões militares comandadas pelos EUA no Iraque e no Afeganistão, além de ter participado do bombardeio à Líbia que culminaria no fim do governo de Muammar al-Gaddafi. Além de participação militar ativa, a Dinamarca (tanto o Estado quanto a sociedade civil) costuma contribuir, proporcionalmente ao seu PIB, com uma parcela significativa de ajuda a organizações internacionais de combate à fome e relacionadas aos direitos humanos. Propagandas de organizações dedicadas a erradicação da fome, de apoio a refugiados de guerra, e campanhas humanitárias são muito comuns no país. Causas relacionadas a outros povos e os direitos humanos também encontram eco dentro do país, como grupos de apoio à causa palestina, sendo, por exemplo, costumeiramente citados por interlocutores como capazes de gerar mais simpatia do que os curdos e outras minorias por sua capacidade de articulação no país.

A ideia de causa curda é, em si, um discurso sujeito a mudanças e a disputas de projeto de poder, desde os que defendem o surgimento de um Estado étnico curdo em todo o território do Curdistão como objetivo principal a ser alcançado até pessoas que defendem o fim do modelo de Estado-nação e a criação de uma sociedade com forte influência anarquista (OCÄLAN, 2011). Passando, ainda, por perspectivas mais pragmáticas nas quais a política de cada país ensejaria reações diferentes da população curda ou mesmo uma luta por maior autonomia curda dentro dos Estados que contêm o Curdistão. De maneira geral e como denominador comum, a causa curda e sua luta seriam uma batalha pela melhora da população curda dentro do Curdistão. Tais distinções também se refletiriam na população curda em diáspora na Dinamarca, havendo diversos relatos em entrevistas e demonstrações relacionadas à identidade curda sobre o que deveria ser feito para resolver essa questão.

Tendo essa disputa em mente, haveria, portanto, grupos que competiriam pelo apoio dentro da população curda e pelo direito de serem as vozes mais influentes em relação aos anseios e desejos da população curdo-dinamarquesa para o Curdistão e, assim, ter influência em relação a políticas governamentais 
em relação a essa nação. Durante as duas manifestações relacionadas ao genocídio perpetrado pelo Estado Islâmico em relação à minoria yazidi em Sinjar, tais disputas entre diversos grupos e entre diversos indivíduos puderam ser observadas, ao mesmo tempo em que o conflito e o confronto entre posições dissonantes eram evitados em tal arena pública. Representantes curdo-dinamarqueses e dinamarqueses eram chamados para discursar publicamente e em relação aos acontecimentos recentes, enquanto políticos membros do Parlamento eram abordados por transeuntes. Veículos da mídia imprensa e televisiva nacionais faziam-se presentes, entrevistando manifestantes e figuras públicas, cobrindo o evento e o transmitindo para a população dinamarquesa de maneira geral. Dentre os políticos dinamarqueses, membros de diversos partidos políticos também participavam, posto que o evento teria atenção nacional. Já entre os indivíduos curdos, membros de diversas organizações eram chamados a dar mensagens públicas sobre a situação de flagrante desrespeito aos direitos humanos dos yazidis que estava ocorrendo.

De maneira geral, durante as duas manifestações organizadas como reação aos ataques perpetrados pelo grupo terrorista Isis ocorridas em frente ao Parlamento Dinamarquês, líderes curdos locais eram chamados a expor suas ideias, como o eram também políticos locais, além deles, acadêmicos e religiosos próximos à população curda. Os discursos eram feitos exclusivamente em dinamarquês, demonstrando uma tentativa de articulação com a população dinamarquesa de maneira geral (somando-se a isso, a presença da mídia dinamarquesa cobrindo o evento). O uso exclusivo do dinamarquês, por exemplo, se opõe ao uso de idiomas curdos em uma manifestação que ocorrera antes de tais eventos e que fora organizada por entidades ligadas ao PKK, contendo discursos em curmânji e cujo o foco exclusivo era a população curda local. Os participantes traziam cartazes com palavras de ordem, organizavam coletas de ajuda financeira e portavam fotos mostrando os crimes cometidos contra os direitos humanos nas montanhas de Sinjar, além de bandeiras curdas, dinamarquesas e americanas. Fieis yazidis também se faziam presentes. Transeuntes paravam para se informar, devido ao volume da manifestação, e eram recebidos por diversos 
indivíduos que entregavam panfletos e buscavam explicar brevemente o motivo de estarem se manifestando. A partir de agora, este artigo analisará a dinâmica presente em ambas as manifestações, focando nas diferenças entre pronunciamentos e sublinhando as disputas locais por influência dentro da população curdo-dinamarquesa, além de lidar com a questão moral que perpassa tal articulação.

\section{MANIFESTAÇÕES, SÍMBOLOS E MORALIDADES: UMA ANÁLISE ETNOGRÁFICA}

Conforme afirmado anteriormente, diversos grupos políticos com interesses em alguns casos conflitantes e, em outros, convergentes estão presentes na população curdo-dinamarquesa. Diversos indivíduos desses grupos amealham capital cultural e posições de liderança, enquanto buscam avançar pontos de vista quanto à melhor maneira de proceder em relação às questões concernentes ao Curdistão. Os assuntos em destaque e compartilhados por tais indivíduos são, em parte, determinados por sujeitos e grupos capazes de moldar o discurso corrente, como o festival anual de cinema curdo, que ocorre em Copenhague, eventos sociais voltados para a população curda na Dinamarca; mas também o são por eventos relacionados à população curdo-dinamarquesa, como o caso do canal ROJ-TV 5 , da vinda de refugiados curdos para a Dinamarca devido à guerra civil na Síria e de eventos correntes que afetam o Curdistão, como o já citado avanço do Isis sobre Sinjar, ou o avanço político do partido HDP, com forte presença curda, na política da Turquia. Em todos esses casos, grupos políticos e sociais curdo-dinamarqueses buscam se consolidar como representantes da população curda, enquanto indivíduos curdo-dinamarqueses buscam atrelar e aumentar seu capital cultural

\footnotetext{
ROJ-TV é um canal curdo ligado ao PKK que começou sua operação na Bélgica e, depois, se muda para a Dinamarca após ser expulso do país. Na Dinamarca, ele seria processado por associar-se ao PKK, em um caso que mobilizaria o governo turco em articulação com o governo dinamarquês e acabaria por mobilizar a população curdo-dinamarquesa em um caso judicial com forte cobertura da imprensa.
} 
ao alcançarem posições de destaque e ao exercerem influência em relação à política dinamarquesa.

Durante tais manifestações, líderes de um grupo político jovem chamado Fokus-A (sigla que significa Organização para Jovens e Acadêmicos Curdos) foram chamados a se manifestar, sob a voz de sua então presidente. Com uma organização que lembra tanto o ideal de representatividade proposto pelo líder curdo Abdullah Ocälan, em sua teoria política do confederalismo democrático, quanto pelas ideias de igualdade de gênero fortemente presentes na Dinamarca, a Fokus-A, durante o meu trabalho etnográfico, cada vez mais se estabelecia com uma organização curdo-dinamarquesa ${ }^{6}$ relevante, especialmente pelo seu papel como iniciadora na trajetória militante e política de diversos jovens curdos na Dinamarca. Em um discurso no qual a luta histórica por liberdade e a constante opressão sofrida pelos curdos ao longo de séculos era reafirmada, a oradora buscava, ao mesmo tempo, reforçar os laços históricos que uniam a população curda espalhada nos quatro estados que ocupam o território do Curdistão e também em diáspora na Dinamarca, por meio de uma narrativa de resistência, sem, entretanto, citar casos específicos. Citava também o quanto as mulheres deveriam ter uma posição de influência cada vez maior e como as mulheres estavam sendo as que mais sofriam devido à ofensiva do Estado Islâmico, ao serem capturadas, escravizadas e, estupradas por membros do grupo fundamentalista. Além disso, o discurso também conclamava aos presentes à necessidade de ajudar a população yazidi que estava, naquele momento, isolada e sem mantimentos, fugindo de um genocídio perpetrado pelo Isis. Portanto, de acordo com o discurso, seria uma obrigação moral da população curda na Dinamarca ajudar os membros de seu próprio povo, especialmente devido ao conforto e à prosperidade com que eles se encontravam na Dinamarca e, assim, citava o trabalho de diversos membros ao arrecadarem

\footnotetext{
6 Por organização curdo-dinamarquesa, entenda-se que há também organizações políticas e sociais nas quais a identidade curda é um fator importante, sem, entretanto, ser o fator mais relevante, conforme descrito por Martin Jørgensen (2008). Há diversos grupos políticos que conjugam identidades políticas de esquerda, identidades políticas relacionadas ao refúgio e imigração ou, ainda, com um contorno étnico não incluso na maioria dinamarquesa. No caso específico de tal campo, a identidade curda era posta em papel de destaque, tanto nos momentos em que articulava-se com questões políticas dinamarquesas como quando não o fazia.
} 
fundos por meio de doações, rifas e outras formas de apoio financeiro. Além disso, o discurso também citaria a obrigação moral da população dinamarquesa de ajudar uma população oprimida por motivos religiosos e étnicos, para isso citaria a história dinamarquesa durante a Segunda Guerra Mundial, em que o país, ao ser invadido pela Alemanha, conseguiria proteger e transportar para a Suécia a maior parte de sua população judia devido ao apoio de sua população. Esse fato histórico inclusive foi citado durante o discurso em uma tentativa de articular a defesa dos direitos humanos de uma minoria oprimida a uma moralidade presente na história recente dinamarquesa. Depois disso, o discurso conclamava os presentes a ajudarem os refugiados yazidis com doações individuais e instigava os políticos dinamarqueses a apoiarem ações do Estado em prol do yazidis em carácter urgente. Tais ações se concretizariam por meio do envio de mantimentos ao local e por ações militares contra o Isis, articuladas com os soldados curdos e iraquianos combatendo em no front.

Em um outro discurso, proferido por um líder mais velho de um grupo político curdo-dinamarquês, salientou-se o papel dos soldados curdos no Iraque, os chamados peshmerga (palavra que significa "aqueles que se encontram com a morte"). Destacou-se também a valentia e o sacrifício de militantes e combatente curdos de outras partes do Curdistão que estariam dispostos a se juntarem ao combate contra a invasão do Estado Islâmico. Ele também lembrou que o sacrifício sofrido pelos curdos no Curdistão deveria servir como forma de mover os curdos em diáspora a atuarem em prol da causa curda e com solidariedade para com os seus "irmãos de sangue no Curdistão". Assim, ele conclamava os participantes a ajudarem e a cobrarem do governo dinamarquês apoio a ações humanitárias e militares na região.

Políticos curdo-dinamarqueses também davam relatos e conclamavam o governo dinamarquês a agir de maneira a proteger a população yazidi, ao mesmo tempo em que se dirigiam à população curda na Dinamarca convocando-a a atuar e a cobrar de representantes políticos dinamarqueses que o respeito aos direitos humanos daquela população fossem um tema importante na pauta política local e que tais manifestações seriam importantes. 
Em relação à população dinamarquesa de maneira geral, políticos afirmavam ser um compromisso histórico a defesa dos direitos humanos por parte do Estado dinamarquês. Já os políticos dinamarqueses (sem origem curda) presentes também reforçariam o papel da Dinamarca na defesa dos direitos humanos, tanto dentro de suas fronteiras quanto fora, como uma questão essencial não só para o Estado dinamarquês, mas para a identidade dinamarquesa. Portanto afirmavam que o país deveria agir, rápida e efetivamente, em relação à situação dos yazidis.

Já o público era composto, em sua imensa maioria, por curdo-dinamarqueses, alguns ativistas dano-dinamarqueses e transeuntes que buscavam se informar sobre o tópico. Somados a eles, havia os veículos da imprensa tanto curdo-dinamarquesa como da imprensa nacional dinamarquesa. Jornais, canais e sites de notícia colhiam entrevistas com organizadores, participantes e políticos presentes. Mulheres vendiam doces e comidas como forma de arrecadar fundos para ajudar a população yazidi, enquanto uma tenda com fotos de mártires curdos envolvidos nas batalhas, civis mortos pelo Estado Islâmico ou levados como presos, encontrava-se no meio do local. Dentro dessa tenda, o clima era de respeito e perplexidade diante da situação precária e da urgência do fato. Algumas pessoas não podiam conter as lágrimas. Enquanto em diversos momentos a manifestação contraía um aspecto mais despojado e um lócus importante de sociabilização, com pessoas conversando entre si sobre amenidades, dentro da tenda o tom era mais solene com as fotos, e as pessoas, ao comentarem sobre algo, o faziam sobre as fotos ou sobre a situação dos yazidis. Tal local adquiria um aspecto de sagrado em uma perspectiva durkheimiana (DURKHEIM, 2008), posto que servia como uma representação de uma narrativa em comum sobre o que seria ser curdo; uma narrativa entremeada por injustiça e por resistência - ambos conceitos constantemente citados em entrevistas e conversas informais. A presença das fotos e o respeito que se mantinha em relação a elas atuava de maneira metonímica ao lidar com os séculos de perseguição curda.

Nesse contexto, as disputas políticas internas da população curdo-dinamarquesa, parte integrante de disputas políticas da população curda 
em si, ocorriam de maneira mais velada. O discurso inicial da representante do Fokus-A, por exemplo, encontrava forte inspiração da teoria política de Abdullah Ocälan e sua perspectiva, na qual o modelo estatal deveria ser eventualmente transcendido, além de seu foco no papel das mulheres e das minorias na construção de uma sociedade mais justa e igualitária, mesmo quando buscava não trazer os conflitos que tal posição política tem dentro da população curda. Palavras-chave utilizadas por ela, para além da escolha de cores e o papel do grupo, seriam suficientes para contextualizar sua fala para qualquer pessoa que conhecesse a dinâmica das disputas internas da população curdo-dinamarquesa; ao mesmo tempo em que ela buscava não entrar em tais disputas de maneira aberta.

Ou seja, ao mesmo tempo em que seu discurso marcava uma posição política clara para qualquer pessoa iniciada, mantinha o tom de conciliação e uma tentativa de colocar o sofrimento da população yazidi e a luta por direitos humanos em primeiro plano. Dentro de uma dinâmica foucaultiana, na qual o poder seria uma estratégia, um modo de ação relacionado a práticas inscritas em tal grupo e que revelaria "uma rede de relações sempre tensas, sempre em atividade" (FOUCAULT, 1976, p. 29), a compreensão dessas redes em constante movimento é essencial para entender as alianças, ligações e rivalidades que levariam a uma trégua, ao menos naquele momento.

O discurso do outro líder, cuja plataforma política para o Curdistão deveria efetivamente passar pela construção de um Estado-nação curdo nos moldes contemporâneos, utilizava-se da mesma estratégia que a líder mencionada ao evitar o confronto político aberto, mantendo os posicionamentos políticos do grupo do qual fazia parte de maneira sutil o suficiente para que ele fosse compreendido, sem criar conflito com vozes dissonantes e sem que o sofrimento dos yazidis não fosse visto como uma forma de buscar apoio à revelia de sua situação.

Assim, o conflito que marcaria a disputa política curdo-dinamarquesa era colocado em um plano publicamente secundário. O momento de luto e de mobilização em prol de uma situação emergencial deveria, de acordo com diversos participantes, ter como prioridade a salvação dos yazidis 
em Sinjar. As disputas internas existentes na população curdo-dinamarquesa sobre a figura de Abdullah Ocälan, a respeito de uma futura existência de um Estado curdo e questões relacionadas a disputas dentro dos quatro Estados que contêm o Curdistão formam a trama social que move grande parte das manifestações políticas relacionadas à etnicidade curda em Copenhague e, portanto, também faziam parte dela. Porém os direitos humanos da população yazidi, ao menos no discurso e em diversas práticas individuais, deveriam se sobrepor, ao menos naquele local e naquele momento, a tais disputas.

É possível observar que há uma moralidade envolvendo os direitos humanos como um conceito capaz de orientar práticas políticas e sociabilidades curdo-dinamarquesas. Haveria um chamado moral, presente tanto nos discursos como nos cartazes e, também, ao conversar com alguns participantes, para que eles, enquanto curdos vivendo em uma sociedade abastada, deveriam apoiar outros curdos em situação de desespero. Ademais, tal apoio deveria ocorrer de maneira a sobrepor, ao menos momentaneamente, qualquer disputa política aberta. Dentro de uma perspectiva weberiana, as relações sociais podem ser vistas como se baseando ou em um "senso mútuo de pertencimento" ou por "motivos racionais" (WEBER, 2019, p. 120), sendo, entretanto, majoritariamente uma combinação de ambas. Assim, o senso de pertencimento a uma coletividade curda serve como substrato moral (e essa moralidade é compartilhada entre os indivíduos curdos e não curdos $)^{7}$ para que tais indivíduos ajam em prol da população curda, ao mesmo tempo em que, racionalmente, tais atores tracem estratégias relacionadas à efetividade de tais ações.

Logo, podiam ser observados na manifestação dois níveis de interação, a depender da identificação étnica dos sujeitos. Para os curdo-dinamarqueses, era um evento de sociabilização focado em sua identidade étnica em comum enquanto curdos. Assim, as disputas políticas que comporiam as redes sociais curdas seriam, ao menos de maneira explícita, colocadas, conforme dito, em um segundo plano. $O$ fato de não estarem completamente ausentes demonstra sua importância e o quanto elas são capazes de serem um elemento extremamente relevante dentro da população curdo-dinamarquesa, assim como a

Sobre a moralidade dentro de uma perspectiva weberiana, ver (STONE, 2010, p. 132-133) 
sutileza com as quais elas eram acionadas também demonstraria tal fator. Portanto, a disputa ideológica entre "idealismo" e "pragmatismo" (WEBER, 2009) estaria perpassando toda a dinâmica política em tais manifestações. Apesar de, naquele momento, o equilíbrio entre os discursos políticos que seriam vistos como mais eficazes na articulação da população curdo-dinamarquesa em prol da situação no Curdistão e as disputas políticas ideológicas entre diversas facções sobre qual seria o caminho correto para a causa curda pender para a primeira opção, as disputas de poder locais estavam bem presentes para quem as soubesse compreender e ler.

Já os indivíduos não curdo-dinamarqueses (e aqui, majoritariamente, lidamos com sujeitos dinamarqueses de diversas origens étnicas) que estavam presentes no local acompanhariam os acontecimentos daquela manhã de verão por meio de vídeos e artigos produzidos pelas agências de notícia presentes em frente ao Parlamento nacional. As manifestações conclamando uma ação militar e humanitária da governo da Dinamarca em prol de uma minoria religiosa - que estava sendo atacada por um grupo terrorista que controlara parte considerável do Iraque e da Síria com o uso da força, governando tais territórios de maneira extremamente intolerante e conservadora, e cometendo diversas formas de desrespeito aos direitos humanos - serviriam como forma de lembrar tais indivíduos sobre o dever moral de agir diante de uma situação de urgência.

Assim, há dois discursos relacionados aos direitos humanos. O primeiro trata a defesa dos direitos humanos como uma obrigação ligada ao pertencimento étnico e à história curda compartilhada por indivíduos em diáspora. Junto com esse discurso, é possível se ver as disputas e a arrumação em torno do capital cultural de diversos indivíduos e de diversos grupos que fazem parte da população curdo-dinamarquesa. O segundo evoca uma tradição dinamarquesa de defesa aos direitos humanos enquanto obrigação moral, inclusive, em diversos momentos, a própria danesidade era conflagrada com a defesa e a manutenção dos direitos humanos. O Estado dinamarquês, como um político diria em discurso, não era somente um Estado responsável pelo bem-estar do povo dinamarquês, mas também deveria se responsabilizar pela defesa 
da vida humana para fora de suas fronteiras, encontrando eco na descrição feita por Richard Jenkins (2006) da moralidade em relação ao igualitarismo presente na construção étnica dinamarquesa. A política externa dinamarquesa, com intervenções militares no Afeganistão e no Iraque, além da política interna dinamarquesa com a presença curda e sua capacidade de articulação política, fizeram o massacre sofrido pelos yazidis se tornar tema importante no discurso político nacional, a ponto de movimentar imprensa e políticos locais, além de tornar uma intervenção estatal dinamarquesa como algo visto como plausível para os manifestantes. Assim, a narrativa sobre proteção de direitos humanos acabaria também sendo manifestada pelos políticos dentro do Parlamento Dinamarquês.

Assim, ambas as narrativas acabam sendo articuladas conscientemente tanto por organizadores quanto por participantes das manifestações. Por parte de diversos participantes entrevistados havia a ideia bastante nítida de que o discurso relacionado aos direitos humanos alcançaria um número grande de pessoas que se comoveriam com a situação crítica de um grupo minoritário diante de uma ofensiva terrorista. Um de meus principais interlocutores, um jovem curdo um dos organizadores dessa e de outras manifestações - cujo pai fora guerrilheiro nas montanhas do Curdistão turco exilado na Dinamarca e a mãe é etnicamente dano-dinamarquesa, afirmaria em conversa informal após a primeira das duas manifestações:

Como curdos, todos nós devemos nos solidarizar com o que acontece com os yazidis em Shingal (Sinjar em curmânci). Nós, aqui na Dinamarca, temos uma série de facilidades, a vida é tranquila e somos abastados. Devemos, portanto, ajudar os outros de nós que passam por dificuldades. E isso tem que ser feito de maneira inteligente. As disputas nossas devem ser deixadas de lado; devemos ser mais unidos, como os palestinos são, por exemplo. E, para isso, nós precisamos também alcançar a população dinamarquesa. Eles ajudaram os judeus na Segunda Guerra Mundial, portanto eles irão ajudar os yazidis que estão passando por uma situação semelhante, caso sejam lembrados disso. 
Sua fala revela, portanto, o desejo explícito por uma articulação política entre a política dinamarquesa e a causa curda. Essa articulação se daria por meio de um discurso moral no qual a defesa dos direitos humanos seria posta como uma causa inapelavelmente justa. Há uma tentativa consciente dos atores políticos curdo-dinamarqueses em coagir, por meio da opinião pública, uma ação do Parlamento Dinamarquês, na qual a defesa de um grupo mais fraco em oposição a uma possível omissão desse grupo teria um custo político bastante claro. Ao mesmo tempo, a fala revela também um desejo de unidade simbólica curda, por meio do chamado a uma luta em comum e, inclusive, pelo uso de referências geográficas em curdo em vez de usar o nome mais usual (originário do árabe). Logo o discurso curdo-dinamarquês também se baseia em uma moralidade que busca tratar os acontecimentos como parte de uma narrativa de defesa contra uma injustiça corriqueira na história curda. A exemplo disso, diversos participantes citariam as inúmeras tentativas históricas de destruição da religião yazidi ao longo dos anos.

Conforme citado, os discursos e práticas em tal manifestação refletiriam, assim, as dinâmicas políticas presentes nos grupos curdo-dinamarqueses e na política dinamarquesa, ao mesmo tempo em que articularia moralidades comuns a ambos os grupos de maneira a alcançar ganhos para os indivíduos em posição de poder (políticos, líderes locais, ativistas), ao passo que servem como forma de expressar um pertencimento a uma comunidade étnica hifenizada e transnacional (curdo-dinamarquesa). A defesa dos direitos humanos da população curda seria vista pela população curdo-dinamarquesa como um imperativo moral - fato explicitado de diversas maneiras pelos participantes e o objetivo dos organizadores e participantes se daria na tentativa de convencer a população dinamarquesa, de maneira geral, a compartilhar sua insatisfação e frustração em relação aos crimes cometidos pelo Isis.

Assim, a defesa dos direitos humanos é instrumentalizada para ganhos políticos por indivíduos e grupos com maior capacidade de aplicá-la, ao mesmo tempo em que se insere em uma narrativa com apelo simbólico para a população dinamarquesa de maneira geral. Para que esse apelo possa ocorrer, há fatores morais que foram amplamente citados e articulados entre si. A ideia de que 
os yazidis deveriam ser protegidos por serem curdos como a maior parte dos manifestantes; que deveriam ser protegidos por serem parte de uma minoria religiosa oprimida; que deveriam ser protegidos por estarem sendo atacados por um grupo que seria uma ameaça à humanidade; que a Dinamarca deveria intervir por ser um dever de impedir um genocídio; que a Dinamarca deveria interferir para evitar que o Isis se expanda para dentro de suas fronteiras - todas essas afirmações surgem em diversos momentos, são articuladas em falas públicas e em conversas com participantes e revelam uma motivação moral, posto que articulam algo bom ou positivo que deve ser feito em oposição a uma situação errada e que não deveria estar ocorrendo. Tais motivações morais revelam também o posicionamento dos sujeitos no que diz respeito a sua posição política e étnica. Há um posição de defesa dos direitos humanos quanto linha em comum entre todos os discursos; já a forma e a motivação para tal defesa variaria e demonstraria a pluralidade de posições e as articulações possíveis entre sujeitos com posicionamentos e perspectivas distintas.

\section{CONCLUSÃO}

Pôde-se observar por meio da experiência etnográfica as maneiras com as quais os discursos sobre direitos humanos e a moralidade são negociados e articulados pela população curdo-dinamarquesa, especialmente certos grupos e indivíduos, e, em menor escala, pela população dinamarquesa em geral, pelo discurso sobre direitos humanos, ao mesmo tempo em que tal moralidade é construída dentro de uma dinâmica interétnica e identitária. Do ponto de vista da população curda, essas articulações estão inseridas em uma narrativa de demonstrações e presença curda na Dinamarca, que se estende desde os anos 1950 chegando até o episódio que serve de base para este artigo, que ocorre em 2014. Os diversos momentos políticos relacionados ao Curdistão têm sido causa para que a população curda em diáspora na Dinamarca se manifeste e se organize. Portanto tais manifestações se insere num contexto mais amplo de organização e disputas, das quais o apoio aos yazidis é somente mais um 
capítulo inserido e interpretado à luz da causa curda enquanto elemento simbólico capaz de mobilizar esses sujeitos.

A percepção da causa curda como transnacional também foi importante na compreensão etnográfica do evento. Um episódio ocorrido no Curdistão iraquiano com uma minoria religiosa levaria a manifestações de populações curdas em diversos países com diáspora curda. Em Copenhague, essas manifestações logo estariam inseridas em um movimento transnacional de identidade curda; assim como estariam as articulações entre grupos curdos e grupos políticos dinamarqueses. Dentro da população curdo-dinamarquesa, identidades políticas se desenvolveriam por intermédio de linhas étnicas, ao passo que o pertencimento étnico seria simbolizado e articulado por pertencimentos políticos. Essas demonstrações são alguns dos lócus preferenciais no quais tais movimentos estariam sendo construídos de maneira mais aberta e clara para seus membros. Assim, trata-se de espaços públicos nos quais a identidade curda estaria sendo abertamente demonstrada.

Para além disso, as manifestações em prol dos yazidis também seriam lócus nos quais a articulação entre identidade curda e identidade dinamarquesa ocorreria, ao mesmo tempo em que a identidade curda seria comunidade para a população dinamarquesa de maneira geral. Essa articulação ocorre em termos morais, nos quais a população dinamarquesa, de maneira geral, é conclamada a conhecer a situação dos yazidi e, de maneira mais focada, os políticos dinamarqueses são exortados a agirem em prol de uma minoria étnica e religiosa em situação de risco. Os discursos, os cartazes e as falas dos presentes, de acordo com eles mesmos, narrariam situações que, para quem quer que os ouvisse, seriam insustentáveis e exigiriam uma ação. Assim, essas situações lidariam, simbolicamente, com conceitos do que seria certo e errado. E nesse percurso, de demonstrar para a população dinamarquesa uma situação claramente errada que deveria ser consertada de maneira imperativa, ocorre uma afirmação étnica da população curdo-dinamarquesa, além de uma série de movimentos entre diversos grupos que a comporiam.

Logo ambas as manifestações estariam inseridas em um contexto de articulação curda na Dinamarca, com grupos políticos dinamarqueses, em 
uma esfera de disputa política de grupos e indivíduos dentro da população curdo-dinamarquesa, ao mesmo tempo em que servem como forma de reafirmação e ressignificação étnica para uma população em diáspora, movimento esse que se articulava de maneira multissituada e transnacional da qual participa a população curdo-dinamarquesa.

\section{REFERÊNCIAS BIBLIOGRÁFICAS}

1. BASER, Bahar. The Kurdish diaspora: identity formation and political activism. Istanbul: Bogaziçi University Press, 2013.

2. DIASPORA Kurde. Fondation Institute Kurde de Paris, Paris, 2016. Disponível em: http://bit.ly/38nJ8LJ. Acesso em: 10 maio 2019.

3. DURKHEIM, Émile. The elementary forms of religious life. Oxford: Oxford Press, 2008. $416 \mathrm{p}$.

4. EDMONDS, C. J. Kurdish Nationalism. Journal of Contemporary History, London, v. 6, n. 1, p. 87-107, jul. 1971.

5. FOUCAULT, Michel. Vigiar e punir. Petrópolis: Vozes, 1975. 296 p.

6. GEERTZ, Clifford. The interpretation of cultures. New York: Basic Books, 1973.470 p.

7. HASSANPOUR, Amir. The creation of Kurdish media culture. In: KEYENBROEK, Philip; ALLISON, Christine (ed.). Kurdish culture and identity. London: Zed Books, 1996. p. $48-85$

8. JENKINS, Richard. Being Danish: paradoxes of identity in everyday life. 2. ed. Copenhague: Museum Tuscalunum Press, 2012. 361 p.

9. JØRGENSEN, Martin Bak. National and transnational identities: Turkish organising processes and identity construction in Denmark, Sweden and Germany.2008. Dissertation (PhD in Migration Studies) - Aalborg University, Aalborg, 2008.

10. JØRGENSEN, Martin Bak. Turks in Denmark: patterns of incorporation and collective organizing processes. Insight Turkey, Istanbul, v. 12, n. 1, p. 163-183, jul. 2010.

11. KHAYATI, Khalid; DAHLSTEDT, Magnus. Diaspora formation amongst Kurds in Sweden: transborder citizenship and politics of belonging. Nordic Journal of Migration Research, Warsaw, v. 4, n. 2, p. 57-64. 2014.

12. MAUSS, Marcel. The gift: forms and functions of exchange in archaic societies. London: Cohen \& West, 1966. 
13. OCÄLAN, Abdullah. Democratic confederalism. London: Transmedia Published, 2011.

14. STONE, Liam. Max Weber and the moral idea of society. Journal of Classical Sociology, Thousand Oaks, v. 10, n. 2, p. 123-136, 2010.

15. THE KURDISH Population. Fondation Institut Kurde de Paris, Paris, 2017. Disponível em: http://bit.ly/2OMg9cs. Acesso em: 19 maio 2019.

16. UNIVERSAL Declaration of Human Rights. United Nations, Geneve, 1948. Disponível em: http://bit.ly/2SkZtuP. Acesso em: 10 maio de 2019.

17. VAN BRUINESSEN, Martin. Kurdish ethno-nationalism versus nation-building states: collected articles. Istanbul: Isis Press, 2000. 301 p.

18. WEBER, Max. Essays in sociology. London: Routledge, 2009. 490 p.

19. WEBER, Max. Economy and society: a new translation. Cambridge: Harvard University Press, 2019. 504 p. 